\title{
Student and teacher perceptions of the differences between "academic" and "vocational" post-16 Media courses
}

\begin{abstract}
Much debate about the relative merit of academic and vocational media courses in the UK is framed by a wider national and international discussion about the status of vocational education more generally. This paper reports the initial findings of a small scale study (set against larger, publicly available data on vocational education) which seeks to examine teacher and student perceptions of the key differences in academic and vocational media courses in the UK - both of which involve elements of production work as well as critical and theoretical perspectives - through a series of interviews with teachers and students, as well as scrutiny of the work they produce. The study hopes to shed some light on the skills, knowledge and criticality required by students on both types of course, as well as beginning to address some of the polarisation that takes place in discourses around academic and vocational education. Rather than suggesting that the choice for students in media education is one of "either vocational or academic", this paper will explore the idea that these two concepts are simply lenses through which students and teachers view very similar kinds of learning.

Keywords: Media Education, Vocational Education, Post- 16 education, Academic education
\end{abstract}

\section{Introduction}

Debates about the place of "vocational" 1 education in secondary and further education in the UK, are often characterised by a number of public narratives that seem to oscillate

\footnotetext{
${ }^{1}$ For the purposes of this paper "vocational" is defined using the criteria identified by Kuchinke (2013), which include 1)recognition of a change from child to adult education 2) preparation for "college or career readiness" and 3) a curriculum that is deliberately differentiated from the wider secondary school curriculum
} 
between two contrasting positions. On one hand, there is an acceptance that vocational education is a necessity for a strong and vibrant economy, while on the other there is a resistance to the idea that vocational education can be intellectually challenging, worthwhile and a viable alternative to academic routes through secondary, further and higher education. This tension is amplified considerably in the fields of Media Studies and Media Education where the public narrative around the subject discipline is generally a negative one anyway (Laughey 2012; Bennett and Kidd 2017) and as a consequence "vocational" media teaching seems to occupy an even more problematic discoursal position - primarily because there appears to be very little consideration of what the implications of such discourses are for students or the wider media industry. 
This article seeks to explore some of these tensions by presenting the findings of a small scale research project, funded by the University of Bedfordshire, looking at the way in which a group of students and teachers involved in both academic and vocational media courses in a large UK secondary school (where both types of course are taught) perceive the teaching and learning they are involved in. The reader is invited to consider this data in the context of more widely available and larger scale data on vocational education from the UK's Centre for Vocational Education research and see it as a means of seeing what the differences between academic and vocational media courses look like in a localised environment. The study identifies two key areas of difference which often come up in the public discourse around both media education and vocational education; namely, content and relative difficulty - neither of which are directly addressed by the much larger CVER data set.

\section{Vocational and Academic Media: An artificial distinction?}

Before outlining the scope of the research, it is important to describe the kind of environment in which it was conducted. At the time of writing, students in post-16 education in the UK who wish to study Media have two routes open to them. They can choose to study an A-Level course in Media Studies or Film Studies; this has

traditionally been seen as an academic route, largely because of the structures imposed on the course by the A-Level format which involve a substantial terminal examination and no more than two assessed practical productions. The other choice available is the 
Level 3 BTEC route (or equivalent) ${ }^{2}$, which has been viewed as a vocational route. This identification has centred on the qualifications focus on continuous assessment, predominance of work-related assignments and lack of a terminal exam (Walden 2016) It should be noted that, in the on-going cycle of qualification reform at post-16, started by the UK government in 2010, a compulsory examination element was introduced to the BTC course in 2017; though the broad tenor of the qualification as a vocational - or at least pre-vocational ( Stafford 1990) - specification has been maintained.

For the purposes of this article, which discusses research conducted in a secondary school environment, where post-16 students are involved in both A-Level and BTEC courses, the distinction is in one sense, clear. Students choose an academic pathway or a vocational one - they cannot do both. However, both in the research findings presented here, and the wider literature surrounding the issue of vocational media education, there is a "blurring of the lines", and indeed one recurring idea that arises from the research is that a distinction between the two routes is neither important or helpful to the students and teachers involved in them. As a consequence of this, it may also be important to consider how helpful any distinction may or may not be to employers in media industries

${ }^{2}$ There are in fact, a number of Level 3 vocational qualifications in Media, some of which are provided by examination boards (such as the OCR Cambridge Technical course) and others by private providers, but the BTEC qualification, provided by Edexcel, is by far the most widespread of these. More information at http://www.accreditedqualifications.org.uk/qualifications-and-credit-framework-qcf.html 
Public Narratives and other Literature: Media, Vocational Education and Vocational

\section{Media Education}

Despite the fact that there is very little substantive research literature regarding vocational media education, the contrast between it and its academic counterpart exist in discussions of media education stretching back more than a quarter of a century (Stafford 1990; Buckingham 1995). These discussions form part of larger debates about both the purpose and status of media education and while there is little in the way of large scale studies of the effectiveness of vocational media courses, there is a constant hum of concern about the relationship between academic and vocational media in the wider conversation. For the purposes of this article then, it is useful to consider the literature in terms of two key themes; firstly, literature focusing on public narratives about media education and the way that vocational media is characterised within those narratives; and secondly literature that directly discusses the status, nature and purpose of vocational media education. The research that follows below attempts to make some connections between these two themes by comparing the way that students and teachers perceive learning in the subject and the way that this may differ (or not) from wider public and theoretical discourses. Space does not permit consideration of the wider literature regarding vocational education as a whole, but there are some points at which this is usefully referred to.

Some recent literature then, has attempted to address in academic terms, the frequently voiced perception of Media Education as a "soft " or "easy" option. Headlines such as "Education chiefs to scrap 14 qualifications including home economics and film studies 
in crackdown on 'easy' subjects" (Daily Mail 2014a) and "Bonfire of 'soft' GCSEs:

Media studies, astronomy and tourism could be axed in bid to make qualification more rigorous" (Daily Mail 2014b) are part of a well-recognised public narrative built on the idea that media education courses are undemanding and not as intellectually rigorous as other curricular subjects. Part of this narrative involves a kind of public bipolarity about vocational education; wherein politicians, business and the media call constantly for more and better vocational education, while at the same time espousing the view that vocational courses are "dumbed down" or in some way inferior to their academic counterparts. In general terms, this view of vocational education as a means of social control has a long history, and a good summary of the debates that have dominated discourses surrounding the topic is given by Atkins and Flint (2015). As they point out, the wholesale adoption of the recommendations made in the Wolf Report (Wolf 2011) have sought to redraw the boundaries of vocational education. Such an exercise has drawn public attention not only to vocational media courses but also to the wider field of media education in that it has raised the question of what the education system in the UK is actually educating its young people for.

Within media education, a number of academics have sought to deal with these tensions, most notably Laughey (2013) and Bennett and Kidd (2017) . For Laughey, one of the strengths of Media Studies is in the tension between the academic and the vocational itself. While acknowledging that one of the criticisms of vocational media courses is that they are often not seen as being sufficiently geared towards industrial practice, he maintains that because the subject sits on the edge of the change that occurs when an economy moves from manufacturing industries to creative ones, media students are ideally placed to adapt to this change. For Bennett and Kidd, the representation of Media Studies as a "soft option" has been made more complex not 
only by the false perception that it is connected with poor employability, but also by the fact that academics might actually contribute to these perceptions by writing and speaking defensively about them.

Furthermore, there has been an explicit attempt to address the question of the extent to which such vocational media courses can be made to prepare students for the demands of work in the media industries. Wardle and Waters (2012) have noted that the proliferation of both vocational and academic Media course has led to a degree of "balkanisation" in the subject where the two types of student are taught in completely separate classes and in completely different ways. This separation, identified by Wardle and Waters, begs the question of whether or not different teaching results in different learning; something that is explored below.

This literature, such as it is, informs this article by raising three key questions. Firstly, what kinds of perceptions do students and teachers have about the relative difficulty and content of these courses, and how does this speak to those tensions within Media education explored by Laughey and Bennett and Kidd? Secondly, to what extent can we make judgements about the way that these courses may or may not prepare students for work in the media industries based on what they say about content and relative difficulty? Finally, what might be said about the different types of knowledge and skills required by these students based on the comments they and their teachers make about these two aspects of their course?

\section{A wider context - available data on the vocational /academic divide in the UK} Because of the relatively small size of this study, it is probably helpful to set the data against the most recent research done in the UK regarding the differences between 
vocational and academic education in the 14-19 age bracket. The Centre for Vocational Education Research (CVER) has published a number of papers in the last two years which help to see the data in this study as part of some bigger trends (Hupkau, McNally et al., 2016; De Coulon, Hedges et al., 2017; Hedges, Patrignani and Conlon, 2018) In summarising some of these findings, it is hoped that the data presented from this study will be given some context; which shows that the public narrative outlined above is largely based on assumption and misconception.

There are three key findings from the CVER work that are pertinent here, but before identifying them, it is worth saying that the CVER research is based on large scale cohort studies which use "big data" freely available in the public domain. Their study of Level 2 learners - the level at which, in the UK, students make choices about what they will do, educationally, after the age of 16 (De Coulon, Hedges et al, 2016) - for example, looks at the course choices and destinations of 65,000 learners.

The three key findings from these studies which are relevant to this paper can be summarised as follows:

1) At Level 3 in the UK qualifications framework, (which is where the courses under discussion in this paper are located) vocational media courses make up more than one fifth of all the BTEC courses taken and more than one third of other vocational media courses. This contrasts with Media and Film A-Levels which only take up a much smaller number of the total number of A-Levels taken (Haupku, MacNally et al, 2016). This observation is based on a cohort of around half a million 16-year olds where around $20 \%$ of that cohort ends up opting for a vocational qualification (ibid, p.30) and around $40 \%$ opt for an academic route (essentially, A-Levels.) This is significant, 
because it gives some sense of how many students are making those choices every year.

2) Regardless of whether or not a young person chooses an academic or vocational route at 16, participation in a Level 3 course is a strong predictor of further success in education or employment (ibid, p.2) and indeed other studies suggest that even non-achievement (failing to satisfactorily pass the course) at level 3 course produces better outcomes than achievement at the level below if the student does not move on to level 3 (Hedges, Patrignani and Conlon, 2018). Given this data, it seems reasonable to suggest that arguments about the relative difficulty of BTEC and A-Level Media courses might be rendered less meaningful if the outcomes that many students (and teachers and policymakers) want are being met by either route.

3)Non-cognitive skills are often more highly valued by employers than cognitive ones (De Coulon, Hedges et al., 2017) - a view echoed in some of literature specifically focusing on vocational media courses (Walden, 2016) The data presented in the study described in this paper suggests that in both routes through Media at post-16, (even allowing for the move toward more synoptic forms of assessment in the vocational route, such as written exams) the balance of both types of skill is quite good, with vocational students being expected to demonstrate good cognitive performance and academic students being expected to excel in the noncognitive through things like group work.

This wider research gives some sense then, of the way that the divide (or lack of it) in academic and vocational media studies is only partially supported by larger data sets. It is not unreasonable to claim that in many ways these level 3 courses are doing what they were designed to at a national level in terms of overall outcomes . 
The CVER work gives a larger picture here, supporting the idea that the situation is not as clear cut as the public narratives would suggest; something that the data from this smaller study also points toward. However, what it does not do is collate data regarding the content of individual courses and their difficulty, and one implication of this is probably that the media industries have more of a role to play in discerning these things.

\section{Materials and Methods}

The study upon which this article is based produced two distinct data sets, only one of which, for reasons of space, is analysed here. The first data set was generated by a series of interviews (of a semi-structured nature, conducted in accordance with the BERA guidelines (BERA 2014) on ethical research) with three teachers and six students and some of these are analysed in some detail below. One interview was conducted with students and teachers towards the beginning of Year 13 (the second year of study for all these students) and another towards the end of the same school Year. In this six month period however, a significant amount of student production work was completed by all the students and the access granted to these finished moving image texts will provide a rich seam of data that can be mined in a future study. It is intended that this production work will be analysed using a multimodal analysis in a future article in order to explore what it might have to say, by way of comparison, about content, relative difficulty and assessment.

The part of the study described in this article is methodologically interpretive in nature, using some principles of discourse analysis established by Norman Fairclough (2001) to 
analyse the interview data with a view to generating an account of the perceived differences between the two routes through Media education available in the school. For Fairclough, the key aspects of discourse that need to be examined in order to get at these power structures are vocabulary, grammar and textual structures. Such an examination allows the researcher to look at the way that power is being enacted through the discourse. In this particular study, this is quite an important idea because some of the narratives around academic and vocational education, and also Media Studies, suggest that certain types of knowledge and educational activity have greater power than others. Limitations of time and space mean that in this account, such an analysis will be quite rudimentary - in this case, focusing almost exclusively on vocabulary - but still valuable in helping to work out how and why the two different routes through media education are perceived in the way they are.

\section{Results: Content and Relative Difficulty}

\section{a) Content}

In the school environment which the students and staff focused on in this article inhabit, both academic and vocational routes have a good deal in common in terms of the kind of practical production tasks that are set and completed. In the six month period of study described here, both the academic and vocational students are engaged in a piece of large scale video production work - and in this particular instance, they are both producing music videos. For the A-Level students, the completed music video must be accompanied by evidence of their research and planning as well as a critical evaluation. (OCR 2013). For the BTEC students, the production of the video itself is part of a wider 
suite of tasks designed to meet the success criteria of a number of units across the course (Edexcel 2010).

These differences are significant because while the outcome of the learning for both groups of students is ostensibly the same (the finished music video) the teaching framework that gets them to that outcome is markedly different. Christina, who is a BTEC student describes these contrasting approaches when talking about working on a friend's music video

"We both (the academic and vocational students) did our music videos at the same time and we had three months to do it I think it was, but we (the vocational students) had many assignments in one... I was in my (friends (A-Level) video and she was in mine, and she was telling me not to stress, because "it's only a draft" and I was like you don't understand, I have to hand this in and it has to be good and then I've only got ten days to improve it if it's not...".

\section{Christina}

Note the use of the word "draft" here. For the A-Level student, the notion of being able to produce a rough cut of the music video, implies the idea that there is the opportunity to experiment; that there is less need for urgency in the production of something that will "not count" for the final assessment. For the BTEC student, however, this version of the finished product is a vital stage in the process that will affect the final mark they receive. Some of these differences in perception can be accounted for by differences in assessment, but at some level there is a difference in the way that the content of each of tasks - and the way their teaching is being structured - is being perceived by both the teachers designing the units and the students completing them. These subtle differences are clearly emphasising different aspects of the production process - in this case 
meeting deadlines and experimentation - and they do raise questions about what is valuable for students in both routes.

Interestingly, there is some difference of opinion here. Mr R. who also teaches on both courses sees the tension described by Christina from an alternative perspective.

"I know some of the team think that there's less room for experimentation in the BTEC course, but I disagree with that, because of the resubmission thing. ..., for example we had one kid, who really knows how to use Adobe After Effects, which is something I'm really weak on, and he just wanted to see how far he could take that in his Music Video project, and he ended up creating something that was a complete failure; it was a really exciting idea but the idea was too broad for the time frame. If that had been an A-Level project, it would have been a disaster - he would have hit the deadline and it would have been over. But with BTEC, he was able to go out and shoot a perfectly good basic music video in the two weeks between the original deadline and the resubmission.I don't think that would have been possible with an A-Level kid. “

\section{Mr R, Media Teacher}

The central issue being described here - namely the acceptance that an idea, no matter how strong it is, may not be realisable - is something that we might consider quite important in preparing students for the world of work. Along with meeting deadlines and the trial-and-error experimentation present in the description of A-Level media, the teacher's ability to create a unit of work in which this issue can be dealt with in a "safe" and low-stakes way is something that many employers would see as being valuable experience. These then, are probably good examples of the "non-cognitive skills" that the CVER data identifies as being useful to employers: deadline meeting, experimentation, pragmatic expectation-management. In drawing attention to all these 
things, and averting the potential "disaster" that might have happened, from the outside we might perceive that $\mathrm{Mr} \mathrm{R}$. is offering insight into the way that his classroom and curriculum planning can prepare students for the world of work. This is problematic, however and some of the difficulties with statements like this will be returned to later in the article.

The way that the similar content of both courses is structured is only one factor that contributes to the perception of how that content might be different. Students' comments about the way they are expected to go about production tasks - in this case creating a music video using digital cameras and software - demonstrate that there is some expectation that what is learnt will be different. One A-Level student, Brian, sums this up quite well;

"The way I see it they (the vocational students) focus more on the hard skills, rather than the theories about why it happens. For them it's more about making it happen. They're more entwined with the software and have a deeper understanding of it.... whereas with ours it's kind of a bit on the side, because we're so focused on understanding these complex theories... that you think well, I can pick that bit up later. To be honest, the quality of their work is a lot better than ours, because....they have more time to get to know what you can get out of the software, whereas we sort of think...ah, that'll do, we'll just throw that in. It takes me by surprise, because people think "Ah, vocational students they just throw it in and it's not as good.", but really it's much better quality than ours."

\section{Brian}

Brian seems to be very explicitly suggesting here that some of the difference in the content of the two courses can be encapsulated in the theory/practice dichotomy. The need to understand "complex theories" might be explained to some extent (again) by the kind of assessment regime that involves a terminal exam, but it also returns to the 
question of what it valuable to the student and the teacher. Brian feels that he is being asked to do something that is not demanded of the BTEC students, but he accepts that demands are made of them in other ways. These value-claims are acknowledged and indeed, perhaps unintentionally encouraged, by teachers, who are very clear about why they exist. Mr D., another senior teacher, who works on both courses, explains that;

"The emphasis in A-Level is much more on taking theory and applying it to an unseen text or to your own case-studies and then taking that through and being able to answer a question about it. With BTEC theory is much more of a guide to help them produce the outcome - they don't necessarily go back and do that rigorous deconstruction in terms of using theory to analyse the product after they have made it. In A-Level if you don't do that stuff, it will affect your grade." $\quad$ Mr. D.

Mr D's use of the word "rigorous" is telling here. As Bennet \& Kidd acknowledge, "rigour" is an important word in the discourses surrounding media education, primarily because people outside the subject sometimes perceive it as being lacking, while the academics and teachers within it are often emphasising why and where rigour is present. There may be a temptation for teachers to equate theory with rigour - a view which is profoundly problematic, not least because, as Brian acknowledges above, the BTEC students, who perhaps spend less time on theory, have what he describes as a "deeper understanding" of some elements of their subject. This is confirmed by another BTEC student, Rachel, who comments that;

"I think we get taught more in depth...I prefer the idea of the vocational because...we do so much, but I think it's more relaxed. We're told what our task is and then left to do it independently. At the very start of year 12 we were taught in a more classroom type way, but now we do it more on our own."

\section{Rachel}


Some of this discourse might also be seen as an attempt to establish what Basil Bernstein calls "strong classification" for the subject of Media Studies as it is characterised in the A-Level course. The idea that theory - in this case, probably semiotic and post-structural analyses - marks out the A-Level Media Studies course as a discipline that is distinctly different to others, is, one would suggest, important when teachers feel that they have to validate their subject in the face of public narratives which deny its importance. Interestingly, both Bernstein (1996) and his collaborator Robert Moore (2000) thought that some interdisciplinary subjects, such as Media Studies, could demonstrate strong classification, provided a number of conditions were met. Connolly \& Readman $(2017,251-253)$ have written about the need to operationalize theory in practice in order for students to become what they term "creatively literate", so the discourse involved in needing to make theory explicit in the two courses suggests a tension that the teachers have not fully resolved; on the academic course, students perceive that they need to operationalize theory more than their practical skills, whereas on the vocational course the reverse seems to be true. One might speculate that neither approach truly meets Connolly \& Readman's criteria.

Teachers and students are both then, aware of the competing claims made about each course, but there is a recognition that this may not fit some of the narratives outlined in the national media discussed earlier. After all, as the CVER research notes, it is quite likely that both groups of students will end up in similar places, post level 3. Such a recognition, does however, lead to a wider discussion of the more complex issue of relative difficulty in the two courses.

\section{b) Difficulty}

For the purposes of this study, it should be emphasised that the data being analysed here concerns perceptions of the relative difficulty levels relating to the two Media courses, 
as held by the students and teachers involved with them. This is significant, because this article is not giving significant consideration to the question of the relative difficulty levels when comparing other subjects to media courses per se. It should be acknowledged, however, that this is something that has concerned academics both in media education specifically (Laughey 2010), and education more widely (Coe 2008). However, such debates serve as an important precautionary warning to the analysis of the data here, and what students and teachers say about the relative difficulty of the ALevel and BTEC Media courses.

A useful example of this complexity is given by Christina, who talks about the role that writing had to play in her BTEC Media course ;

"I am going to do a more theory based course at University...I've discovered that I am actually much better at theory based stuff...but BTEC has helped me a lot, because I'm not very good at exams. I'm much better at the coursework part of my courses...I'm much better at sitting down and writing an essay about something than I am at filming it, but ...I can think of so many amazing ideas for something like a music video, that I knew I had to pick the one that I'd be able to go out and film. So I would say I'm a very creative person, but I'm better at writing ideas down...(writing) is the way I get my creativity out best. “

\section{Christina}

A closer look at Christina's use of language here suggests some ambiguities to the concept of difficulty as it is often framed in narratives around educational challenge or “hardness". Using Fairclough's (2001, 94-95) idea of the experiential value of words, and what particular words reflect about knowledge and belief, the isolation of a number of specific utterances here highlight this. Take the phrase "I'm not very good at exams". One of the public narratives around vocational courses is that they are easy because they tend to involve methods of continuous assessment, rather than terminal 
examination. Christina's description of herself here reflects a certain degree of experience within an education system which demands that students sit regular examination and that these have presented her with certain difficulties. In one sense then, the public narrative about vocational media courses is being implicitly confirmed. However, the phrase she uses later on in this section of the interview, where she says "I'm much better at sitting down and writing an essay about something than I'm at filming it", presents a challenge to such a narrative. At this level, what is an examination, if it is not "sitting down and writing an essay about something"? We might expect, given some of the publicly-held low expectations of vocational media students, that they joined their particular course in order to avoid writing, but for this student, the demands of the course have allowed them to become more confident in an ability normally perceived as being reserved for those who wish to demonstrate academic excellence. Additionally, while the word "creativity" is an ideologically contested term (Readman 2011), its use here does suggest that its attachment to the vocational - or at, least to what Wardle \& Waters (2012) term "the applied" - is something to be questioned. As Banaji et al. (2010) point out, there are many ways to be creative, and not all of them necessarily need to be associated with making things.

As Christina acknowledges and perhaps, contrary to Brian's view, "theory" does play a part in the BTEC course. Mr D. expands on this a little more in his interview and also suggests that the relative difficulty of theoretical ideas sits in relationship to the way that they are used by students within the course:

"I think, in the pre-production phase, they do have to consider ideas like codes and conventions, a lot on representation, a lot on institutional issues, but what I would call higher level representational theory, stuff like postmodernism, you simply don't do that on the BTEC course, or not in the same way... but its more theory that's "fit for 
purpose", so I guess you could say it's the product driving the theory where in the other one (A-Level) its theory driving the product."

Mr D.

This would suggest that the notion of "fit for purpose" is coming from the specifications themselves; some theoretical ideas will have more value in one course than they do in the other. However, a phrase like "higher level representational theory" implies that there is a hierarchy of ideas at work here, and this is why it is necessary to consider assessment methods, and the way that they might be used to organise that hierarchy. In this school environment, where the two different courses run alongside each other, questions are raised regarding certain types of knowledge having more value than others. Though space does not permit it here, a closer look at the assessment of both courses might reveal something of the nature of these values.

\section{Discussions /Conclusions}

In the initial discussion of the (admittedly limited) literature relating to the subject of this article, three questions were posed about perceptions, preparation for work and knowledge and skills. In addition to these questions generated by the literature, there was also a wider question of how much difference there really is between the two courses being scrutinised here. The findings of this research can only begin to provide some answers to these questions, but the data presented here does suggest that the differences between the two types of course do not easily fit the public narrative about either vocational media courses or media courses more generally. With regard to perception, it is clear that the students from both routes perceive challenges in each other's courses. Some of these perceptions are to do with what might broadly be termed "theory" and in the context of the interviews conducted here, theory can broadly be characterised as a range of post-structuralist and semiotic theories. The idea that theory is one area of difficulty appears to be held and/or reinforced by teachers who see using 
theory and writing about it as something rigorous and challenging, though as has been noted, there is theory of varying kinds and varying challenge in both qualifications. However, it is also clear that for students in the academic route, there is a perceived level of technical skill that they do not believe they will reach. We might expect such distinctions to be made by students who are presented with two different routes through media education; what is perhaps more surprising is the way that the students interviewed here perceive the vocational course as presenting greater opportunity for both writing and more in-depth thinking.

The question of whether or not either of these routes prepare students for work is a vexed one; indeed, the question of whether or not they should actually attempt to do this at all, when they are not really designed and delivered by employers, makes the whole question of the connection between qualification and employability very troubling particularly if both types of courses are a similar indicator for further success ((Hedges, Patrignani and Conlon, 2018). We might expect, for both students and teachers, that the path from BTEC course to the creative industries is a clear (if steep) one. However, the generally problematic nature of the transition from school to either work or HE is highlighted here as well; as Mr D. explains when talking about the two groups of students.

"Generally in the BTEC cohort some kids have a much more "I want to work in the industry" attitude. In A-Level five years ago I would have said that 90\% would have said "I want to go to University", but that has changed noticeably with the way that the finding structure (i.e. tuition fees) has changed. “

Mr D. 
So while there are work-related and economic themes that are pursued by both teachers and students, the actual relationship between them and the eventual work or study destination of the young person is more complex. While these complexities are, to some extent, tied up with the personal circumstances of the student, it is tempting to speculate that some of the perceptions about the relative difficulty of the two courses and their relationship with work or further study are generated by the institutions surrounding them (the school and its culture, the exam board, the university) rather than the people involved in them directly, and that these contribute to the public narratives discussed earlier. It probably takes a bold 18 year old to defy being interpellated (in the Althusserian sense) by some of the ideas which surround post-16 study, Higher Education and work.

Some of these discussions about work and study also connect with what the students and teachers here are saying about knowledge and skills. The students here are clear that different kinds of knowledge and skills appear to be valued by each course (see Brian and Christina's comments), but on closer examination, the theory/practice divide is not as clear as their comments suggest. It seems reasonable to point out here that some of the "blurring of the lines" between the two courses is an environmental consequence of being in a school which teaches both courses, with a similar staff team to groups of students who are in the same pastoral groupings. Such an observation could also lead however, to the view that many of the distinctions between the two routes could be entirely artificial. The students in this particular school have avoided seeing these distinctions because of the way that the staff deliver their subject. Despite their own views about certain kinds of knowledge being more important than others, they have managed to straddle the theory/practice divide quite successfully, creating an 
environment where both choices are valid, regardless of the public narratives which surround them.

In conclusion then, two points need to be made. Firstly, the data discussed here, despite being from a very small sample, when set against the wider CVER data, does offer a challenge to some of the public narratives that surround both media education and vocational education more generally, presenting as it does a more nuanced and complex perspective on these two routes through this particular subject area. Secondly, a number of key questions require further exploration; for example, how will the introduction of a compulsory exam component in the vocational course affect students' perceptions of its difficulty levels? What kind of relationship does an academic Media course bear to its HE counterparts? How does theory taught at A-Level affect the students' ability to take on new (and perhaps contradictory) theoretical knowledge in HE? Such questions are it seems, significant if both students and teachers are to understand fully the implications of a qualification system which makes a distinction between the academic and vocational. 


\section{References}

Atkins, L. \& Flint, K. 2015. 'Nothing changes: perceptions of vocational education in England', International Journal Of Training Research, 13, (1), 35-48

Banaji, S., Burn, A. \& Buckingham, D. 2010. The Rhetorics of Creativity: A literature review. 2nd ed. London: Creativity, Culture and Education.

Bennett, L, \& Kidd, J. 2016, 'Myths about media studies: The construction of media studies education in the British press', BASE

BERA 2014 Ethical Guidelines for Educational Research. Available at https://www.bera.ac.uk/researchers-resources/publications/ethical-guidelines-foreducational-research-2011 (accessed 10/11/17)

Bernstein, B. 1996. Pedagogy, Symbolic Control and Identity: Theory, Research, Critique. London: Taylor \& Francis 
Buckingham, D. 1995. 'Media Education and the Media Industries: Bridging the gaps?' Learning Media and Technology, 21 (1), 7-20

Coe, R. 2008. 'Comparability of GCSE examinations in different subjects: an application of the Rasch model.' Oxford Review of Education, 34, 609-636.

Connolly, S. \& Readman, M. 2017 'Towards "Creative Media Literacy"' International Handbook of Media Literacy Education. De Abreu, B., Mihailidis, P., Yee, A., Melki, J. \& McDougall,J. (eds) Oxford: Routledge.

Daily Mail .2014a. 'Education chiefs to scrap 14 qualifications including home economics and film studies in crackdown on 'easy' subjects' available at http://www.dailymail.co.uk/news/article-2647882/Education-chiefs-scrap-14qualifications-including-home-economics-film-studies-crackdown-easy-subjects.html (accessed 10/11/17)

Daily Mail.2014b. 'Bonfire of 'soft' GCSEs: Media studies, astronomy and tourism could be axed in bid to make qualification more rigorous' Available at http://www.dailymail.co.uk/news/article-2645486/Michael-Gove-set-axe-soft-GCSEsincluding-media-studies-astronomy-tourism-bid-make-qualification-rigorous.html (accessed 10/11/2017)

De Coulon, A., Hedges, S., Nafilyan, V., and Speckhesser, S. 2017. Young people in low level vocational education: characteristics, trajectories and labour market outcomes CVERDP004, Centre for Vocational Education Research, London School of Economics.

Edexcel. 2010. BTEC Level 3 Creative Media Production Specification. Available at http://qualifications.pearson.com/en/qualifications/btec-nationals/creative-mediaproduction-2010.html

Fairclough, N. 2001. Language and Power. Harlow : Longman.

Hedges, S. , Patrignani, P and Conlon, G. .2018. Setting the Counterfactual Debate: Is there a preferable counterfactual when estimating the returns to vocational 
qualifications? CVERDP001, Centre for Vocational Education Research, London School of Economics.

Hupkau, C, McNally, S., Ruiz-Valenzuela, J. and Ventura, G. 2016. Post-Compulsory Education in England: Choices and Implications, CVERDP013, Centre for Vocational Education Research, London School of Economics.

Kuchinke, K.P. 2013. 'Education for Work: A Review Essay of Historical, CrossCultural, and Disciplinary Perspectives on Vocational Education', Educational Theory, 63, 2. 203-219,

Laughey, D. 2010. 'Trial by Media: The Case For and Against Media Studies in the UK Press.'Presented at the Media Literacy Conference, London.

Laughey, D. 2012. 'Media Studies 1.0: Back to Basics' Media Education Research Journal. 2 (2) pp.57-64

Moore, R. 2000. 'The (Re)Organisation of Knowledge and Assessment for a Learning Society: the constraints on interdisciplinarity', Studies In Continuing Education, 22, (2) 183-199,

OCR - Oxford Cambridge \& RSA Examinations. 2013. AS \& A-Level GCE Media Studies Specification. Available at http://www.ocr.org.uk/Images/81037specification.pdf

Readman, M. 2011. 'Inspecting creativity: Making the abstract visible.' Media Education Research Journal, 2 (1).57-72.

Stafford, R. 1990. 'Redefining Creativity: Extended Project Work in GCSE' in Watching Media Learning: Making Sense of Media Education ed. D. Buckingham. London: Falmer Press

Walden, V.G. 2016. 'How can BTEC teachers support young people to be prepared for careers in the media industries? A reflection on pedagogy' Journal of Media Practice, 16 (3). 263-277. 
Wardle, J \& Walters, E. 2012. 'Creative and Media Diploma' in Scarratt, E. \& Davison, J. eds.The Media Teacher's Handbook. London: Routledge

Wolf, A. 2011. Review of Vocational Education - The Wolf Report. DFE 